\title{
Comparative Performance Evaluation of Conventional and Renewable Thermal Insulation Materials Used in Building Envelops
}

\author{
Benjamin DURAKOVIC, Gokhan YILDIZ, Mohamed E. YAHIA
}

\begin{abstract}
In the past decades, insulation materials such as petrochemical and inorganic have been used for building insulation. The production of these insulation materials consumes a large amount of energy, which has a significant effect on the environment throughout the life cycle. Comparative performance analyses of renewable (natural) insulation materials for building application in terms of their impact on the environment, the useful lifetime, cost, insulation performance, thermal diffusivity water vapor resistance and flammability were analyzed using statistical tools. It was found that renewable insulating materials have competitive performances with traditional nonrenewable materials in terms of heat insulation performances, fire resistance and cost. Also it was found that renewable materials have significantly better performances such as less impact to the global warming, longer useful lifetime, and lower thermal diffusivity.
\end{abstract}

Keywords: building insulation materials; material performances; natural /renewable materials

\section{INTRODUCTION}

Today, the vast majority of energy needs are provided by fossil fuels. The increase of energy demand is shortening the life of fossil fuels at the same time. For this reason, reducing the dependence on fossil fuels in energy production [1] has become a necessity in this century [2].

Today, people are constantly looking for new ways to live in better conditions using active systems [3] and at the same time it increases the demand for energy [4]. From the published research it is seen that the largest portion of the energy is used by industry and housing [5]. The biggest share of the energy consumed in homes is the energy used for heating and cooling [6].

Therefore, thermal insulation of building envelope in the past decades becomes inevitable element in building energy demand reduction [7], which is caused by the exterior and interior temperature difference [5]. Various kinds of insulation materials (traditional materials) for building application have been rapidly growing, but recently there are many initiatives to use environmentally friendly materials, which still have a negligible share in the market [8].

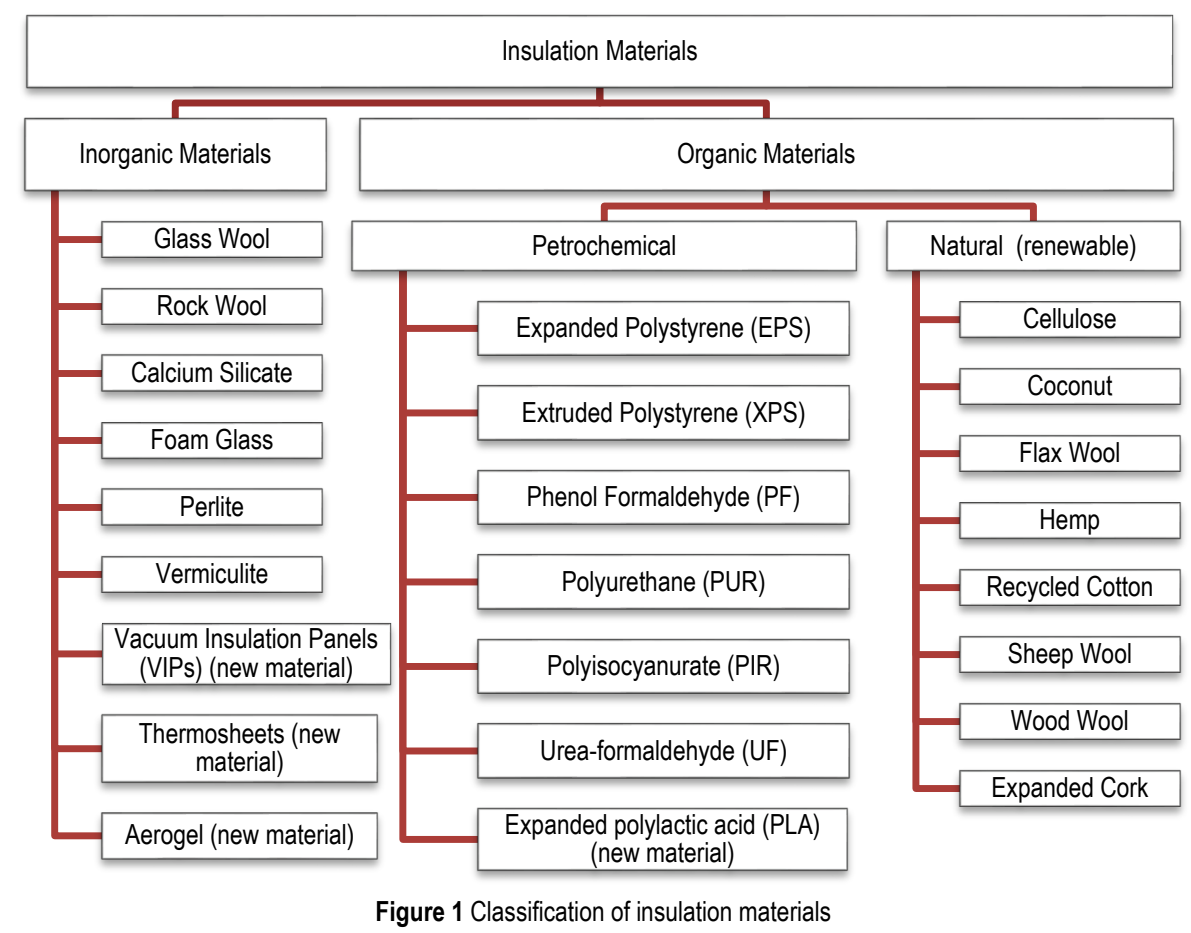

During the life cycle, traditional insulation materials have notable impact to the global warming, thus they play an important role in environmental pollution [9]. Many studies have been conducted with the aim of looking for new ways for reducing building energy demands as part of its continuous improvement [10]. Different insulation materials were proposed that are more efficient and more environmentally friendly as well as appllication of materials in building components that have energy storage capacity [11][12][13]. Natural insulation materials become attractive for researchers as substitute for the traditional [14]. Some of them have comparable thermal properties 
and they may have improved thermal and moisture buffering [15]. Therefore, they may provide a more sustainable and healthy environment with the possibility to be recycled [16].

All insulation materials for building applications are classified in three groups such as inorganic, organic and new technology materials [17]. This classification is shown in Fig. 1.

Inorganic materials are considered as traditional materials such as glass wool, rock wool, calcium silicate, foam glass, perlite and vermiculite. Organic materials are separated in two groups. These groups are petrochemical and renewable materials. Petrochemical materials are considered as traditional as well and contain expanded polystyrene (EPS), extruded polystyrene (XPS), phenol formaldehyde, polyurethane, polyisocyanurate and urea formaldehyde. Renewable insulation materials are considered as more environmentally friendly such as cellulose, coconut, flax wool, hemp, recycled cotton, sheep wool, woo wool and expanded cork. New materials are thermosheets, aerogels, expanded polylactic acid and vacuum insulation panels (VIP).

The focus of this study is on renewable, inorganic and petrochemical materials. Advantages and disadvantages of particular material reported in Fig. 1 are discussed in the literature. It was observed that results from a study to study vary in both ways, positive and negative. Therefore, it is difficult to say whether renewable materials perform well or not as group. In this study, all these results were collected, categorized and analyzed using statistical tools at $95 \%$ confidence interval. Material performances highly differ from a material to a material, but the question is not answered whether renewable materials as a group are competitive with traditional materials as another group. The goal of this study is to investigate what advantages and disadvantages renewable materials have as a group; and whether these materials have the other comparable performances with traditional insulation materials to be competitive in the market. To carry out the study, the following questions were investigated:

1) Are there comparable thermal properties between these two groups of materials?

2) Do renewable materials have significantly lower global warming potential?

3) What is useful life time for each of them?

4) Is there significant difference in cost?

5) Do renewable insulation materials have significantly better thermal diffusivity properties?

6) Is there significantly high resistance to water between them?

7) Is there a significant difference in fire resistance between them?

8) What materials have higher energy consumption during life cycle (production process)?

Some of these questions were partially answered in the literature for a certain material without providing a whole picture. This study investigates the question and provides answers for the material groups by comparing their performances. Particular material performances are collected from the literature, categorized and reported in Tab. 1.

\begin{tabular}{|c|c|c|c|c|c|c|c|c|}
\hline Inorganic & $\mu(-)$ & $\alpha\left(\mathrm{m}^{2} / \mathrm{s}\right)$ & $\operatorname{Cost}\left(€ / \mathrm{m}^{3}\right)$ & $\begin{array}{c}\begin{array}{c}\text { Energy Cons. } \\
(\mathrm{MJ} / \text { f.u. })\end{array} \\
\end{array}$ & $\begin{array}{c}\text { Global Warm. } \\
\left(\mathrm{CO}_{2} / f . u .\right)\end{array}$ & $\begin{array}{c}\text { Fire Class } \\
(-) \\
\end{array}$ & $\begin{array}{c}\text { Useful lifetime } \\
\text { (years) }\end{array}$ & References \\
\hline Glass wool & $1-1.1$ & $(2 \mathrm{E}-06)-(5.33 \mathrm{E}-07)$ & $77.5-147$ & 229.02 & 9.89 & 1 & $30-50$ & {$[17][18][19]$} \\
\hline Rock wool & $1-1.3$ & $(7.5 \mathrm{E}-07)-(2 \mathrm{E}-07)$ & $102.08-179.5$ & 63.34 & 3.62 & 1 & $30-50$ & {$[17][18][19]$} \\
\hline Calcium Silicate & $6-20$ & $(3 \mathrm{E}-07)-(2.7 \mathrm{E}-07)$ & $95-285$ & 55.8 & 4.25 & 1 & N/A & {$[18][20]$} \\
\hline Foam glass & 400 & $(3.8 \mathrm{E}-07)-(2.8 \mathrm{E}-07)$ & $357.38-445.5$ & 208 & 19.439 & 1 & $50-80$ & {$[17][18][19]$} \\
\hline Perlite & $2-3$ & $(6.3 \mathrm{E}-07)-(5 \mathrm{E}-07)$ & 207.89 & 67.31 & 3.99 & 1 & $\mathrm{~N} / \mathrm{A}$ & {$[17][18][21]$} \\
\hline Vermiculite & $2-3$ & $(1.5 \mathrm{E}-06)-(4.7 \mathrm{E}-07)$ & 152.6 & 53.37 & 3.36 & 1 & N/A & {$[17][18][21]$} \\
\hline \multicolumn{9}{|l|}{ Petrochemical } \\
\hline Exp.polystyrene & $20-70$ & $(1.7 \mathrm{E}-06)-(1 \mathrm{E}-06)$ & $61.42-186.56$ & 118.67 & 8.25 & $6-7$ & 50 & {$[17][18][19]$} \\
\hline Extruded polystyrene & $80-300$ & $(4.6 \mathrm{E}-07)-(5.9 \mathrm{E}-07)$ & $156-180$ & 127.31 & 13.22 & $6-7$ & 50 & {$[17][18][19]$} \\
\hline Phenol formaldehyde & $30-50$ & $(4.2 \mathrm{E}-07)-(1.1 \mathrm{E}-07)$ & 302.63 & 52 & 3.508 & $3-5$ & $\mathrm{~N} / \mathrm{A}$ & {$[18][22]$} \\
\hline Polyurethane & $30-170$ & $(1 \mathrm{E}-07)-(5.6 \mathrm{E}-07)$ & 303.78 & 99.63 & 6.51 & $5-7$ & $30-50$ & {$[17][18][19]$} \\
\hline Polyisocyanurate & $55-150$ & $(4.6 \mathrm{E}-07)-(5.4 \mathrm{E}-07)$ & $250.1-286.6$ & 65.08 & 3 & $5-7$ & $\mathrm{~N} / \mathrm{A}$ & {$[18][23]$} \\
\hline Ureaformaldehyde & $1.5-2.4$ & $(2.5 \mathrm{E}-06)$ & 400 & 112.4 & 10.2 & $5-6$ & N/A & {$[18][24]$} \\
\hline \multicolumn{9}{|l|}{ Natural/renewable } \\
\hline Cellulose wool & $1.7-3$ & $(4.2 \mathrm{E}-07)-(2.6 \mathrm{E}-07)$ & 175.71 & 19.39 & 0.73 & 6 & N/A & {$[17][18]$} \\
\hline Coconut & $1-10$ & (1.7E-07)-(1.9E-07) & 482 & N/A & N/A & 6 & N/A & {$[18]$} \\
\hline Flax (flax wool) & $1-2$ & $(1.1 \mathrm{E}-06)-(2.5 \mathrm{E}-07)$ & 116.77 & 49 & 2.36 & 4 & N/A & {$[18][25]$} \\
\hline Hemp (hemp wool) & $1-2$ & (7.5E-07)-(2.9E-07) & 108.1-138.93 & 35.55 & 0.26 & 6 & N/A & {$[17][18]$} \\
\hline Recycled cotton & $1-2$ & $(9.8 \mathrm{E}-07)-(6.1 \mathrm{E}-07)$ & 138 & N/A & $\mathrm{N} / \mathrm{A}$ & 6 & N/A & {$[18]$} \\
\hline Sheep wool & $1-3$ & $(2.1 \mathrm{E}-06)-(9.4 \mathrm{E}-07)$ & 200 & 17.12 & 1.46 & 6 & 100 & {$[17][18]$} \\
\hline Wood wool & 5 & $(3.3 \mathrm{E}-07)-(2 \mathrm{E}-07)$ & $190-236.44$ & 255.36 & 1.56 & 6 & 75 & {$[17][18][19]$} \\
\hline Expanded cork & $5-30$ & $(2 \mathrm{E}-07)-(1.5 \mathrm{E}-07)$ & $155.9-319.14$ & 378.65 & 5.93 & 6 & 80 & {$[17][18][19]$} \\
\hline
\end{tabular}

The functional unit $(f . u$.) is defined as the mass of insulation material that involves a thermal resistance value of $1 \mathrm{~m}^{2} \mathrm{~K} / \mathrm{W}$ and the area of $1 \mathrm{~m}^{2}$ for a service life period of 50 years [4]:

$$
\text { f.u. }=R \lambda \rho A,
$$

where, $R$ is thermal resistance in $\mathrm{m}^{2} \mathrm{~K} / \mathrm{W}, \lambda$ is thermal conductivity in $\mathrm{W} / \mathrm{mK}, \rho$ is specific mass in $\mathrm{kg} / \mathrm{m}^{2}$, and $A$ is unit area in $\mathrm{m}^{2}$.

\section{METHOD}

To investigate the problem and to find the answer to the previous questions, statistical tools that include hypothesis testing were applied. To find significant difference in performances among these three groups of insulation materials, Analysis of Variance (ANOVA) and post-hoc tests were applied. Post hoc $t$-test was used to investigate which group differs significantly from the others. 
ANOVA technique separates the variability of data amongst the different factors. It helps test certain hypothesis concerning the parameters of the model, or estimates the components of the variance [10][26][27]. The data were grouped and analyzed using method described in Tab. 2 .

Table 2 General data matrix for ANOVA [28

\begin{tabular}{|c|c|c|c|c|c|c|}
\hline $\begin{array}{l}\text { Material } \\
\text { group }\end{array}$ & \multicolumn{4}{|c|}{ Observations } & Totals & Averages \\
\hline 1 & $y_{11}$ & $y_{12}$ & $\ldots$ & $y_{1 n}$ & $y_{1}$. & $\bar{y}_{1}$. \\
\hline 2 & $y_{21}$ & $y_{22}$ & $\ldots$ & $y_{2}$ & $y_{2}$. & $\bar{y}_{2}$. \\
\hline . & . & . & $\ldots$ & . & . & . \\
\hline . & . & . & $\ldots$ & . & . & . \\
\hline$a$ & $y_{a 1}$ & $y_{a 2}$ & $\ldots$ & $y_{a n}$ & $y_{a}$ & $\bar{y}_{a}$. \\
\hline & & & & & y.. & $\bar{y}$. \\
\hline
\end{tabular}

Referring to the matrix in Tab. 2, $y_{i j}$ is the $j$-th observation taken in the material group $i$, $\bar{y}_{i}$. is an average value of observation in group $i$, $\bar{y}_{\text {. }}$ is an average value of all observations for each material in group $i, a$ is the number of material groups, $n$ is the number of observations in each group. Whole matrix was organized in a way that considers the same number of observations for each group of material (treatment). The data in the matrix actually represent a linear statistical model and can be written as:

$y_{i j}=\mu+\tau_{i}+\varepsilon_{i j}\left\{\begin{array}{l}i=1,2, \ldots, a \\ j=1,2, \ldots, n\end{array}\right.$,

where, $y_{i j}$ is a random variable with $n$ observations, $\mu$ is the mean value for certain group, $\tau_{i}$ is an $i$-th material group effect, $\varepsilon_{i j}$ is an error component. Total sum of squares was calculated as:

$S S_{\mathrm{T}}=S S_{\mathrm{Gr}}+S S_{\mathrm{E}}$,

where, $S S_{\mathrm{Gr}}$ is sum of squares of material groups, $S S_{\mathrm{E}}$ is error sum of squares.

These three sums of squares were determined using the following formulas:

$$
\begin{aligned}
& S S_{\mathrm{T}}=\sum_{i=1}^{a} \sum_{j=1}^{n}\left(y_{i j}-\bar{y}_{. .}\right)^{2}, \\
& S S_{\mathrm{Gr}}=n \sum_{i=1}^{a}\left(\bar{y}_{i .}-\bar{y}_{. .}\right)^{2}, \\
& S S_{\mathrm{E}}=\sum_{i=1}^{a} \sum_{j=1}^{n}\left(y_{i j}-\bar{y}_{i} .\right)^{2},
\end{aligned}
$$

Observed value of $F_{0}$-test was determined as the ratio between mean sum of squares of material groups $\left(M S_{\mathrm{Gr}}\right)$ and mean sum of squares of error $\left(M S_{\mathrm{E}}\right)$.

$$
F_{0}=\frac{S S_{\mathrm{Gr}} /(a-1)}{S S_{\mathrm{E}} /[a(n-1)]}=\frac{M S_{\mathrm{Gr}}}{M S_{\mathrm{E}}} \text {, }
$$

where, $(a-1)$ represents degrees of freedom of the numerator (between the groups), $a(n-1)$ represents the degrees of freedom of the denominators (error). The calculated value of $F_{0}$-statistics was compared with corresponding critical value $\left(F_{\text {cr }}\right)$ taken from standard literature for significance level of $\alpha=0.05$, and for appropriate degrees of freedom of numerator and the nominator.

The following two main cases were observed: If $F_{0}>$ $F_{\text {cr }}$ (or $p$-value $<\alpha$ ), there is no significant differences between the groups of materials. If $F_{0}>F_{\text {cr }}$ (or $p$-value $>$ $\alpha$ ), it was considered that there is significant difference between the groups of material for certain performance.

Table 3 Single-Factor ANOVA summary table [29]

\begin{tabular}{|l|c|c|c|c|}
\hline Variation Sources & $\begin{array}{c}\text { Sum of } \\
\text { Squares }\end{array}$ & $\begin{array}{c}\text { Degrees of } \\
\text { Freedom }\end{array}$ & $\begin{array}{c}\text { Mean } \\
\text { Square }\end{array}$ & $F_{0}$ \\
\hline Material groups & $S S_{\mathrm{Gr}}$ & $a-1$ & $M S_{\mathrm{Gr}}$ & $\frac{M S_{\mathrm{Gr}}}{M S_{\mathrm{E}}}$ \\
\hline Error & $S S_{\mathrm{E}}$ & $a(n-1)$ & $M S_{\mathrm{E}}$ & \\
\hline Total & $S S_{\mathrm{T}}$ & $a n-1$ & & \\
\hline
\end{tabular}

Overall, obtained significance from ANOVA model indicates that there is at least one significant difference between material group means but it does not indicate which pair differs significantly. To identify the differences for all pairs, post-hoc comparison $t$-tests were used. In this case upper significance level was corrected using the following Bonferroni correction.

$\alpha_{\text {cor }}=\alpha / m$,

where, $m$ represents number of comparison, while significant difference was identified for each $p$-value $\leq \alpha_{\text {cor }}$.

Assuming unequal variances of the material groups $\left(\sigma_{1}^{2} \neq \sigma_{2}^{2}\right)$ and having determined corrected significance level, significant differences in mean performances were determined by using a two-sample $t$-test. The following cases were checked: $\mu_{1} \neq \mu_{2} ; \mu_{1}>\mu_{2} ; \mu_{1}<\mu_{2}$.

Where, $\mu_{1}$ and $\mu_{2}$ represent the mean performances of material one and material two.

Observed $t$-test statistics is calculated using unequal variance case as:

$$
t_{0}=\frac{\bar{x}_{1}-\bar{x}_{2}-\Delta_{0}}{\sqrt{\frac{s_{1}^{2}}{n_{1}}+\frac{s_{2}^{2}}{n_{2}}}}
$$

The following cases were observed: if $p$-value $<\alpha_{\text {cor }}$, there is no significant differences between the groups of materials. If $p$-value $>\alpha_{\text {cor }}$, it was considered that there is significant difference between the groups of material for certain performance. These tests were performed usig commercial SPSS software package.

\section{RESULTS AND DISCUSSION}

Performances of three groups of building insulation materials were tested using one way ANOVA at 95\% confidence interval. The results obtained from SPSS software regarding performances such as fire resistance, water vapor resistance, thermal diffusivity, cost and insulation performance, global warming potential and useful lifetime are shown in Tab. 4. 
Table 4 ANOVA Results

\begin{tabular}{|c|c|c|c|c|c|c|}
\hline \\
\hline & & Sum of Squares & $\mathrm{df}$ & Mean Square & $F_{0}$ & $p$-value \\
\hline \multirow{3}{*}{ Fire Resistance } & Between Groups & 189.525 & 2 & 94.763 & 150.805 & $.000 *$ \\
\hline & Within Groups & 23.250 & 37 & .628 & & \\
\hline & Total & 212.775 & 39 & & & \\
\hline \multirow{3}{*}{ Vapor Resistance Factor } & Between Groups & 47531.276 & 1 & 47531.276 & 5.208 & $.028 *$ \\
\hline & Within Groups & 346778.299 & 38 & 9125.745 & & \\
\hline & Total & 394309.575 & 39 & & & \\
\hline \multirow{3}{*}{ Thermal Diffusivity } & Between Groups & 4737.846 & 2 & 2368.923 & 101.138 & $.000 *$ \\
\hline & Within Groups & 866.641 & 37 & 23.423 & & \\
\hline & Total & 5604.488 & 39 & & & \\
\hline \multirow{3}{*}{ Cost } & Between Groups & 25705.619 & 2 & 12852.809 & 1.046 & .362 \\
\hline & Within Groups & 454852.517 & 37 & 12293.311 & & \\
\hline & Total & 480558.136 & 39 & & & \\
\hline \multirow{3}{*}{ Energy Consumption } & Between Groups & 2714.766 & 2 & 1357.383 & .130 & .879 \\
\hline & Within Groups & 156431.612 & 15 & 10428.774 & & \\
\hline & Total & 159146.378 & 17 & & & \\
\hline \multirow{3}{*}{ Global Warming Potential } & Between Groups & 116.054 & 1 & 116.054 & 6.155 & $.025^{*}$ \\
\hline & Within Groups & 301.702 & 16 & 18.856 & & \\
\hline & Total & 417.756 & 17 & & & \\
\hline \multirow{3}{*}{ Useful Lifetime } & Between Groups & 5386.111 & 2 & 2693.056 & 10.005 & $.002 *$ \\
\hline & Within Groups & 4037.500 & 15 & 269.167 & & \\
\hline & Total & 9423.611 & 17 & & & \\
\hline
\end{tabular}

From Tab. 4 it is observed that significant difference in performances among the groups of the insulation materials exist (starred values) but it is not clear which group differs significantly. To determine which group differs significantly post-hoc $t$-tests were used with the correction $\alpha_{\text {cor }}=\alpha / m=0.05 / 3=0.0167$. The results are shown in Tab. 5.

Table 5 Comparative $t$-test results

\begin{tabular}{|c|c|c|c|c|c|}
\hline Dependent Variable & (I) Material1 & (J) Material 2 & Mean Difference (I-J) & $p(T \leq t)$ one-tail & $p(T \leq t)$ two-tail \\
\hline \multirow{3}{*}{$\begin{array}{l}\text { Energy consumption } \\
\text { (MJeq per f.u.) }\end{array}$} & \multirow{2}{*}{ Inorganic } & Petrochemical & 16.95833 & 0.323 & 0.646 \\
\hline & & Natural & -13.0383 & 0.429 & 0.858 \\
\hline & Petrochemical & Natural & -29.9967 & 0.324 & 0.648 \\
\hline \multirow{3}{*}{$\begin{array}{c}\text { Global warming } \\
\text { potential (kg } \mathrm{CO}_{2} \mathrm{eq} \\
\text { per f.u.) }\end{array}$} & \multirow{2}{*}{ Inorganic } & Petrochemical & -0.02317 & 0.497 & 0.994 \\
\hline & & Natural & 5.374833 & 0.038 & 0.077 \\
\hline & Petrochemical & Natural & 5.398 & 0.006 & 0.013 \\
\hline \multirow{3}{*}{ Useful lifetime (years) } & \multirow{2}{*}{ Inorganic } & Petrochemical & 1.666667 & 0.421 & 0.842 \\
\hline & & Natural & -35.8333 & 0.004 & 0.009 \\
\hline & Petrochemical & Natural & -37.5 & 0.001 & 0.001 \\
\hline \multirow{3}{*}{ Cost $\left(€ / \mathrm{m}^{3}\right)$} & \multirow{2}{*}{ Inorganic } & Petrochemical & -60.2975 & 0.087 & 0.175 \\
\hline & & Natural & -10.0167 & 0.410 & 0.821 \\
\hline & Petrochemical & Natural & 50.28083 & 0.122 & 0.245 \\
\hline \multirow{3}{*}{$\begin{array}{l}\text { Thermal diffusivity } \alpha \\
=\lambda / \rho \cdot c p\left(\mathrm{~m}^{2} / \mathrm{s}\right)\end{array}$} & \multirow{2}{*}{ Inorganic } & Petrochemical & $-0.02 *$ & 0.000 & 0.000 \\
\hline & & Natural & $-0.0009^{*}$ & 0.019 & 0.039 \\
\hline & Petrochemical & Natural & $0.022 *$ & 0.000 & 0.000 \\
\hline \multirow{3}{*}{$\begin{array}{c}\text { Vapor resistance factor } \\
\qquad \mu(-)\end{array}$} & \multirow{2}{*}{ Inorganic } & Petrochemical & -9.87 & 0.424 & 0.848 \\
\hline & & Natural & 65.42 & 0.050 & 0.100 \\
\hline & Petrochemical & Natural & $75.30^{*}$ & 0.001 & 0.002 \\
\hline \multirow{3}{*}{ Fire class } & \multirow{2}{*}{ Inorganic } & Petrochemical & $4.75^{*}$ & 0.000 & 0.000 \\
\hline & & Natural & $4.75^{*}$ & 0.000 & 0.000 \\
\hline & Petrochemical & Natural & 4.75 & 0.5 & 1 \\
\hline
\end{tabular}

*significant at $p<0.0167$

The results shown in Tab. 4 and in Tab. 5, are discussed in details below.

\subsection{Energy Consumption}

The results from Tab. 4 indicate that natural/renewable insulation materials have comparable thermal properties as traditional ones and may be advantageous in thermal and moisture buffering. The mean performances between the materials are listed in Tab. 5, which suggests that natural/renewable insulation materials have a higher value of the mean energy consumption indicating a lower performance as insulating materials. Judging only from this difference it is not enough to claim that natural/renewable insulating materials have notable lower performances in energy consumption. Another piece of information ( $p$-value) must be taken in the consideration as well. From the table, a high $p$-value $=0.87$ indicates that there is no significant difference between the two groups of materials. Thus, natural/renewable materials have comparable insulating capabilities with the conventional materials, and the difference in the means of energy consumption between these two groups is negligible.

Conventional materials were broken in two groups (inorganic and petrochemicals). Another test was conducted to compare if there is any difference among inorganic, petrochemicals and natural/renewable groups of materials with $95 \%$ confidence interval. The results 
from in Tab. 5 show Bonferroni test results for energy consumption, $p=0.88$ and indicates that there is no significant difference in energy consumption applying different types of the building insulation materials. In other words, all materials perform similarly as insulators. The same conclusion is confirmed with Bonferroni test, there is no significant difference in energy consumption if any of three groups of the building insulation materials is used.

\subsection{Global Warming Potential}

Natural/renewable insulation materials have significantly lower global warming potential compared to traditional materials. Producing insulation materials from petrochemical or natural/renewable sources (glass and stone wool) always involves high energy consumption causing higher impact to the environment. A comparative analysis of global warming potential between natural/renewable and conventional materials was done and results are shown in Fig. 2.

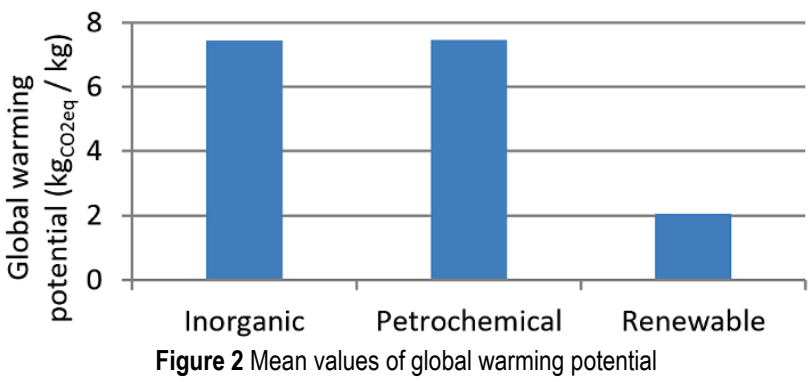

ANOVA results from Tab. 4 indicate significantly higher impact of conventional materials on global warming than natural/renewable materials $(p=0.024)$. To determine which group differs significantly in this test, post-hoct-test test was conducted. Referring to Tab. 5, global warming potential of inorganic and petrochemical materials does not differ significantly, while natural/renewable materials have significantly lower impact to the environment compared to petrochemical insulation materials. Comparing natural/renewable materials with inorganic, significantly lower impact of renewable materials to the environment was not found.

\subsection{Useful Lifetime}

Natural/renewable insulation materials have significantly longer useful life time compared to traditional materials. Useful lifetime is an important performance of an insulation material. Fig. 3 shows renewable materials have useful lifetime over 80 years on an average value.

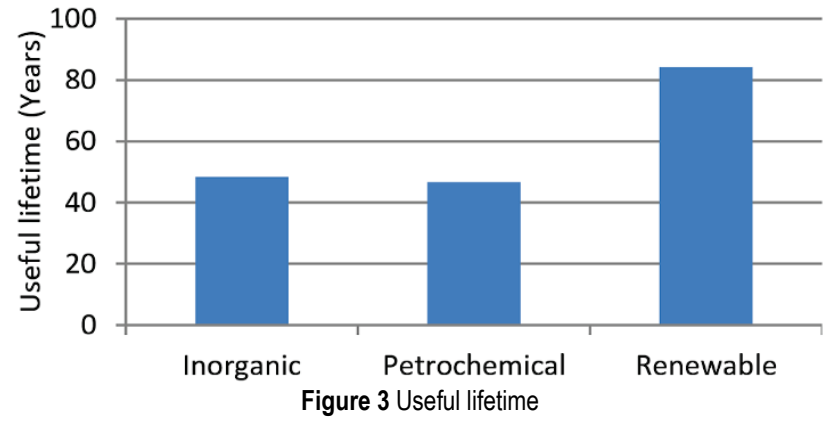

ANOVA table shows that there is at least one significant difference among the group of materials ( $p=$ $0.002)$. The difference is identified using $t$-test analysis. Referring to Tab. 5, it is found that renewable materials have significantly longer useful life-time than inorganic and renewable ( $p$-values for two-tail are 0.009 and 0.002 are less than 0.017).

\subsection{Cost Performances}

Natural/renewable insulation materials have competitive cost with traditional insulation materials. It is found that there is no significant difference in cost performances among insulation material. Referring to Tab. $5, p$-value is greater than $5 \%$, suggesting that renewable materials have competitive price. Fig. 4 shows cost average values of one cubic meter of insulation material, which is in the span of 200 to $260 \mathrm{EUR} / \mathrm{m}^{3}$.

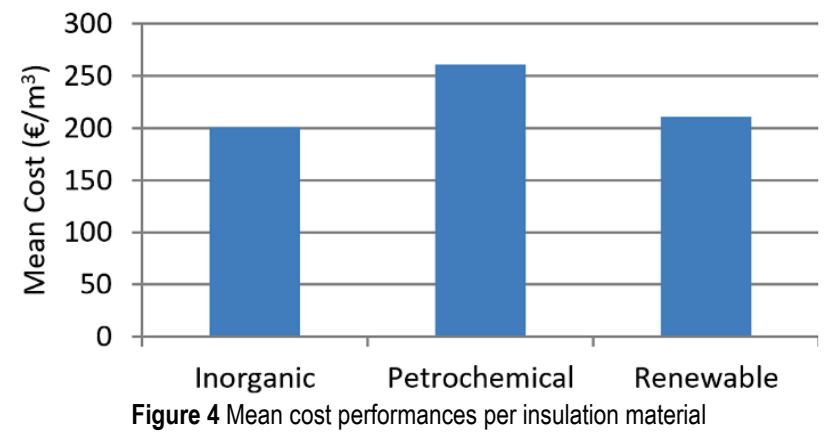

\subsection{Thermal Diffusivity}

Natural/renewable insulation materials have significantly lower thermal diffusivity compared to petrochemical materials. Thermal diffusivity is property of a material describing how fast an insulation material reacts to temperature change during transient heat conduction. An insulation material with a high thermal diffusivity conducts heat quickly from one side to the other side. $p$-value in ANOVA model indicates that at least one group differs significantly. Referring to Tab. 5, natural/renewable materials compared to petrochemical have significantly lower thermal diffusivity which places these materials as better performing. Fig. 5 shows thermal diffusivity values in $\mathrm{m}^{2} / \mathrm{s}$.

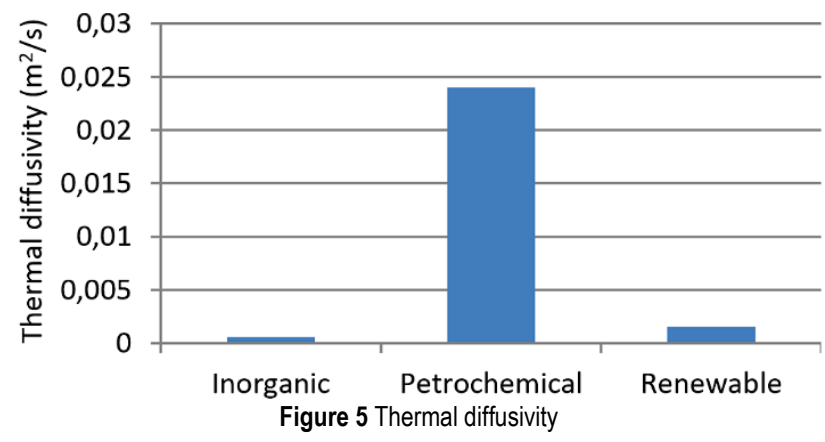

Comparing to petrochemical, inorganic and natural/renewable materials perform better, they have very low thermal diffusivity placing them as more competitive in this case. 


\subsection{Vapor Resistance Factor}

Vapor resistance factor represents a relative resistance of an insulation material to let water vapor pass through. Referring to Tab. $4 p$-value in ANOVA model indicates that at least one group differs significantly. From Tab. 5, $p$ $=0.001$ indicating that natural/renewable materials have significantly lower values of resistance factor than petrochemicals. Fig. 6 shows water vapor resistance factor as an unitless number.

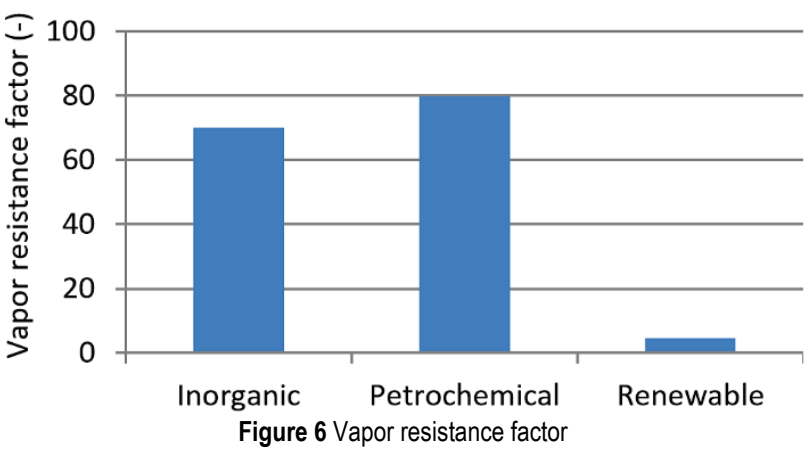

Thus, natural/renewable materials are considered as more breathable contributing to occupant comfort than conventional insulation materials. Their breathable property allows moisture to dry from the material and to prevent its accumulation over time.

\subsection{Fire Resistance Performances}

Natural/renewable insulation materials have significantly lower fire resistance performances than inorganic but there is no significant difference between renewable and petrochemical insulation materials. In Tab. $5, p=0$ indicates that inorganic materials have significantly better fire resistance performances than petrochemical and renewable materials. Also, comparative results between renewable materials and currently in use petrochemical materials show that significant difference to fire resistance does not exist.

Table 6 Fire resistance classes

\begin{tabular}{|l|c|c|}
\hline \multicolumn{1}{|c|}{ Description } & Class & Rank \\
\hline the best & A1 & 1 \\
\hline very good & A2 & 2 \\
\hline good & B & 3 \\
\hline medium & C & 4 \\
\hline poor & D & 5 \\
\hline very poor & E & 6 \\
\hline cannot be classified & F & 7 \\
\hline
\end{tabular}

The fire resistances of building insulating materials are classified in different fire resistance classes from A1 to F. Inflammable materials are considered as the best and placed in class A1. Those materials that are very flammable and those materials that still have no fire class determined are placed in F class, as it is defined in EN 13501-1 (Fire classification of construction products and building elements. Classification using test data from reaction to fire tests.). The fire resistance rank used in this study is shown in Tab. 6.

Since many renewable materials have no fire class determined yet, they are placed in F class in this analysis.
As the result they show low performances in this case compared to the inorganic but similar to petrochemical materials. Fig. 7 shows the average ranks values for each group.

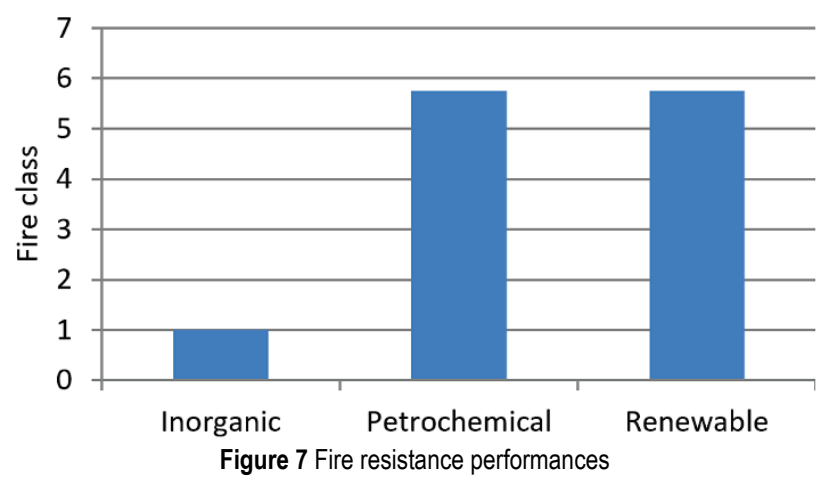

Since many natural/renewable materials have no fire class determined yet, the worst case scenario was analyzed in this study. Once the fire class gets determined for them, it is expected that some of them will have higher fire resistance and better ranking than it is reported in the literature and it may lead to be significantly different from petrochemicals as well.

\section{CONCLUSION}

This study showed that natural/renewable insulation materials such as paper wool, flax wool, hemp wool, recycled cotton, sheep wool, and wood wool etc., which often can be found locally in many regions, have comparable thermal properties and costs with conventional materials such as inorganic and petrochemical. Fire resistance of natural/renewable materials is comparable with petrochemicals but significantly lower compared to inorganic material. Also it is found that natural/renewable materials have significantly lower global warming potential, thermal diffusivity and water vapor resistance than conventional materials, which can be considered as advantages over conventional material. Based on these findings, natural insulation materials are recommended to be used in building design due to their low thermal conductivity that causes a high thermal resistivity, saves the energy dissipation and reduces enviromental impact.

\section{REFERENCES}

[1] Du, H., Carpenter, K., Hui, D., \& Radonjic, M. (2017). Microstructure and micromechanics of shale rocks: case study of marcellus shale. Facta Universitatis Series: Mechanical Engineering, 15(2), 331-340. https://doi.org/10.22190/FUME170602016D

[2] Asdrubali, F., Pisello, A. L., D’Alessandro, F., Bianchi, F., Cornicchia, M., \& Fabiani, C. (2005). Innovative cardboard based panels with recycled materials from the packaging industry: thermal and acoustic performance analysis. Energy Procedia, 78, 321-326. https://doi.org/10.1016/j.egypro.2015.11.652

[3] Ghazanfari S. A. \& Wahid, M. A. (2018). Heat transfer enhancement and pressure drop for fin-and-tube compact heat exchangers with delta winglet-type vortex generators. Facta Universitatis Series: Mechanical Engineering, 16(2), 233-247. https://doi.org/10.22190/FUME180117024G 
[4] Ardente, F., Beccali, M., Cellura M., \& Mistretta, M. (2008). Building energy performance: A LCA case study of kenaffibres insulation board. Energy and Buildings, 40, 1-10. https://doi.org/10.1016/j.enbuild.2006.12.009

[5] Ghaffarianhoseini, A., Dahlan, N. D., Berardi, U., Ghaffarianhoseini, A., Makaremi, N. \& GhaffarianHoseini, M. (2013). Sustainable energy performances of green buildings: A review of current theories, implementations and challenges. Renewable and Sustainable Energy Reviews, 25, 1-17. https://doi.org/10.1016/j.rser.2013.01.010

[6] Moretti, E., Belloni E., \& Agosti, F. (2016). Innovative mineral fiber insulation panels for buildings: Thermal and acoustic characterization. Applied Energy, 169, 421-432. https://doi.org/10.1016/j.apenergy.2016.02.048

[7] Janković, A., Antunović, B. \& Preradović, L. (2017). Alternative method for on site evaluation of thermal transmittance. Facta Universitatis Series: Mechanical Engineering, 15(2), 341-351. https://doi.org/10.22190/FUME170419017J

[8] Benkreira, H., Khan, A., \& Horoshenkov, K. (2011). Sustainable acoustic and thermal insulation materials from elastomeric waste residues. Chemical Engineering Science, 66, 4157-4171. https://doi.org/10.1016/j.ces.2011.05.047

[9] Volf, M., Diviš, J., \& Havlík, F. (2015). Thermal, moisture and biological behaviour of natural insulating materials. Energy Procedia, 78, 1599-1604. https://doi.org/10.1016/j.egypro.2015.11.219

[10] Duraković, B. \& Bašić, H. (2013 ). Continuous Quality Improvement in Textile Processing by Statistical Process Control Tools: A Case Study of Medium-Sized Company. Periodicals of Engineering and Natural Sciences, 1(1), 3646. https://doi.org/10.21533/pen.v1i1.15

[11] Durakovic, B. \& Torlak, M. (2017). Experimental and numerical study of a PCM window model as a thermal energy storage unit. International Journal of Low-Carbon Technologies, 12(3), 272-280. https://doi.org/10.1093/ijlct/ctw024

[12] Durakovic, B. \& Torlak, M. (2017). Simulation and experimental validation of phase change material and water used as heat storage medium in window applications. $J$. of Mater. and Environ. Sci., 8(5), 1837-1746.

[13] Duraković, B. \& Mešetović, S. (2019). Thermal Performances of Glazed Energy Storage Systems with Various Storage Materials: An Experimental study. Sustainable Cities and Society, 45, 422-430. https://doi.org/10.1016/j.scs.2018.12.003

[14] Athayde, J. N., Fernandes, B. L., Siqueira, C. J. d. M., Nohama, P., \& Fernandes, C. R. (2018). Device for in vitro wear analysis of biomaterials in the hinged prosthesis configuration. Facta Universitatis Series: Mechanical Engineering, 16(3), 381-388. https://doi.org/10.22190/FUME170623030A

[15] Mounir, S., Khabbazi, A., Khaldoun, A., Maaloufa, Y., \& Hamdouni, Y. E. (2015). Thermal Inertia and Thermal properties of the composite material Clay-wool. Sustainable Cities and Society, 19, 191-199. https://doi.org/10.1016/j.scs.2015.07.018

[16] Casals, X. G. (2006). Analysis of building energy regulation and certification in Europe: their role, limitations and differences. Energy and Buildings, 38, 381-392. https://doi.org/10.1016/j.enbuild.2005.05.004

[17] Duijve, M. (2012). Comparative assessment of insulating materials on technical, environmental and health aspects for application in building renovation to the Passive house level.

[18] Schiavoni, S., D'Alessandro, F., Bianchi, F., \& Asdrubali, F. (2016). Insulation materials for the building sector: A review and comparative analysis. Renewable and Sustainable Energy Reviews, 62, 988-1011.

https://doi.org/10.1016/j.rser.2016.05.045
[19] Papadopoulos, A. M., Karamanos, A., \& Avgelis, A. (2002). Environmental Impact of Insulating Materials at the End of Their Useful Lifetime.

[20] Korjenic, A., Klarić, S., Hadžić, A., \& Korjenic, S. (2006). Sheep Wool as a Construction Material for Energy Efficiency Improvement. Energie, 8, 5766-5781. https://doi.org/10.3390/en8065765

[21] Ricciardi, P., Belloni, E., \& Cotana, F. (2014). Innovative panels with recycled materials: Thermal and acoustic performance and Life Cycle Assessment. Applied Energy, 134, 150-162. https://doi.org/10.1016/j.apenergy.2014.07.112

[22] Su, X., Luo, Z., Li Y., \& Huang, C. (2016). Life cycle inventory comparison of different building insulation materials and uncertainty analysis. Journal of Cleaner Production, 112, 275-281. https://doi.org/10.1016/j.jclepro.2015.08.113

[23] Pargana, N., Pinheiro, M. D., Silvestre, J. D. , \& Brito, J. d. (2014). Comparative environmental life cycle assessment of thermal insulation materials of buildings. Energy and Buildings, 82, 466-481. https://doi.org/10.1016/j.enbuild.2014.05.057

[24] Silva, D. A. L., Lahr, F. A. R., Varanda, L. D., Christoforo, A. L., \& Ometto, A. R. (2015). Environmental performance assessment of the melamine-ureaformaldehyde(MUF) resin manufacture: a case study in Brazil. Journal of Cleaner Production, 96, 299-307. https://doi.org/10.1016/j.jclepro.2014.03.007

[25] Asdrubali, F. (2006). Survey on The Acoustical Properties of New Sustainable Materials for Noise Control. Euronoise 2006, Tampere.

[26] Basic, H. \& Durakovic, B. (2012 ). Textile Cutting Process Optimization Model Based On Six Sigma Methodology In a Medium-Sized Company. Journal of Trends in The Development of Machinery and Associated Technology, 16(1), 107-110. https://doi.org/10.21533/pen.v1i1.15

[27] Durakovic, B., Demir, R., Emek, C., \& Abat, K. (2018). Lean Manufacturing: Trends and Implementation Issues. Periodicals of Engineering and Natural Sciences, 6(1), 130143. https://doi.org/10.21533/pen.v6i1.45

[28] Durakovic, B. (2017). Design of Experiments Application, Concepts, Examples: State of the Art, Periodicals of Engineering and Natural Scinces, 5(3), 421-439. https://doi.org/10.21533/pen.v5i3.145

[29] Montgomery, D. C. (2009). Statistical Quality Control, $6^{\text {th }}$ ed., John Wiley.

\section{Contact information:}

Benjamin DURAKOVIC, PhD, Assist. Professor

(Corresponding author)

International University of Sarajevo

Hrasnicka cesta 15, 71000 Sarajevo, Bosnia and Herzegovina

E-mail: bdurakovic@ius.edu.ba

Gokhan YILDIZ, MS student

International University of Sarajevo

Hrasnicka cesta 15, 71000 Sarajevo, Bosnia and Herzegovina

E-mail: gokhan.yildiz1987@hotmail.com

Mohamed E. YAHIA, PhD, Assist. Professor

International University of Sarajevo

Hrasnicka cesta 15, 71000 Sarajevo, Bosnia and Herzegovina

E-mail: myahia@ius.edu.ba 